\title{
END-OF-LIFE CARE FOR OLDER RURAL PEOPLE: JUST BEING THERE
}

\author{
Barbara Horrell \& Christine Stephens
}

\begin{abstract}
This paper discusses the experience of caring for someone over 65, with a terminal illness, in rural New Zealand. The narratives from seven participants contextualise complex lived realities, potentially informing future rural end-oflife (EoL) care and contributing to contemporary goals of positive ageing and dying well. Positioning themselves as carers, rather than as rural people, the participants speak about similar issues, with diverging perspectives reflecting their different carer standpoints. Limited access to 24 hour support and specialist palliative care services, and negotiating complex needs are juxtaposed with the joys and rewards of caring. Ambivalence and conflict permeate the stories, reflecting a particular socio-historical moment as, caught between two paradigms of care, the participants vacillate between desiring the empathic, compassionate care of yesteryear and the benefits of modern medical technology. Overall however, therapeutic relationships unambiguously emerge as the most valued aspect of quality EoL care.
\end{abstract}

\section{INTRODUCTION}

Although how we die is unique to every individual (Feifel, 1990; McKechnie et al., 2007), the dying process is 'typically an experience lived out in social contexts' (Corr et al., 1999, p. 241). Family, friends, informal and formal carers, and health specialists interact with dying people as well as with each other to share, or withhold, information and support. Relationship networks such as these construct particular experiences of dying (Hedtke \& Winslade, 2004). From a wider perspective, each experience is located within historical, cultural, and political contexts. These create the identifiable patterns (Walter, 1994) and the cultural scripts (Seale, 1998) we use to respond to dying and death, which in turn, influence the kind of end-of-life (EoL) care people expect and receive. This paper adds a contextualised perspective to the existing literature on dying 
well by discussing the experience of caring for dying people in a specific geographical and historical context: rural New Zealand in the early 21st Century.

\section{BACKGROUND}

A contemporary discourse that considers dying a normal, natural process and argues that family, friends and neighbours should be supported to take back the responsibility of caring for dying people in their own communities (Byock et al., 2001) is increasingly influencing how we think about EoL care. New Zealand's Positive Ageing Strategy (Ministry of Social Development, 2001) provides support for this ideal through its goal of ageing-in-place. This Strategy and the Health of Older People Strategy (Ministry of Health, 2002) guide the service provision of care for older people in this country. Underpinning these strategies are concepts of independence, autonomy and choice that ostensibly enable people to choose where they live and die and the kind of care they receive. However, this also perpetuates a neo-liberal focus on 'the individual' that may not be conducive to quality EoL care. In recent years, Hospice, as a concept of care for people in the end-stage of any disease, has moved into community-based settings such as patients' homes, residential facilities and community or rural hospitals (Twycross, 2007). The New Zealand Palliative Care Policy (Ministry of Health, 2001) supports this move, acknowledging the need for local decision-making and community-oriented services. More recently the Carers' Strategy and Five Year Action Plan (Ministry of Social Development, 2008) highlighted the important contribution made by informal carers and provides guidelines to support their caring role in the community. Together these initiatives have the potential to strengthen the interdependent relationships that this study argues are crucial to dying well.

Many older people retire to rural areas for the lifestyle and scenery, to reduce the cost of living, and with the expectation that smaller communities are more cohesive and supportive (Davis \& Bartlett, 2008) ${ }^{1}$. However, as a result of economic restructuring and down-grading of services (Chalmers \& Joseph, 1998), these perceived benefits are counteracted by limited resources and services, especially with regard to healthcare (Kelley, 2007). The delivery of high quality palliative care, in particular, is variable and a key issue for rural areas (Goodridge \& Duggleby, 2010). At the same time, traditional family and social support networks are slowly eroding due to the mobility of younger people and more transient families (Putnam, 2000). This has contributed to labour shortages, making it difficult to fill carer roles for home support and residential care, which places an extra burden upon those who are already carers, especially older people who are informally caring for each other (Seymour 
et al., 2005).

Older rural people who do not have the social networks, family carers and other resources that allow them to age-in-place may move away from the smaller rural areas to be closer to more specialised medical care (Horrell \& Day, 2007). Others, who choose to remain where their roots and friends are, may spend their last weeks or days in residential or hospital care because there is no 24 hour care available to them at home. Thus, the traditional rural death (DeSpelder \& Strickland, 2005) stereotypically portrayed as a 'good death', at home, surrounded by family and friends, is becoming less achievable. Furthermore, despite a contemporary discourse that promotes dying at home as ideal, the wish to die at home cannot be assumed. McNaught's (2002) New Zealand study found that dying at home was not highly ranked by participants as an important factor for dying well. Similarly, Gott et al. (2004) found that although older people wanted friends and family around them when they died this did not necessarily mean they wanted to die at home. Payne et al. (2001) suggest that in reality, many rural people rely on hospital or residential care at the end of life.

In New Zealand, Hospice care varies between regions. For example, the West Coast of the South Island has no community hospice, and in Canterbury one hospice services up to 450,00o people (Hospice New Zealand, 2005). Moreover, not all patients take advantage of Hospice support, relying instead on hospitals and primary care providers for care. Thus, people dying in rural areas depend on GPs, primary health care nurses, and district nursing services which may be limited due to staff shortages. This puts pressure on nursing staff and increases the likelihood of burn-out (Casey et al., 2005). Furthermore, caring for someone that you know personally is especially emotionally draining (Dunham et al., 2003), and maintaining professional boundaries between work and personal lives is difficult in a small community (Goodridge \& Duggleby, 2010).

Wilson et al. (2006) argue for more support and training for rural nurses and other palliative care providers. This need for support also extends to family caregivers. Providing physical care and witnessing the physical problems of their loved ones are the most frequently reported stressful experiences for family carers (Wilkes \& White, 2005). It is interesting that although the New Zealand Carers' Strategy (Ministry of Social Development, 2008), has the potential to help the carers of dying people, it focuses mainly on long-term carers of people with disabilities rather than a terminal illness. While care may be provided for only a few months, weeks or even days, it is typically intensive, both physically and emotionally. Rural women especially, tend to bear the 
brunt of the caregiving (Crosato \& Leipert, 2006) and even though caregivers may be committed and well-intentioned, the caring experience is challenging and exhausting (Wilkes $\&$ White, 2005), especially for older carers.

The EoL care research identifies better education, information sharing and training as key areas for improved quality of care. This is also evident in the rural literature (Wilkes et al. 2000; Kelley et al., 2004; van Vorst et al. 2006). Although the variability of specialist rural palliative care services means that primary care providers play a key role in EoL care, Evans et al's (2003) literature review of rural palliative care organisation and rural health professional's views, found little information about GP's perspectives and needs. Although not specifically a rural study, Walker \& MacLeod's (2005) study found important knowledge gaps among South Island GPs, including not knowing the appropriate response to certain palliative care emergencies. Similarly, Mitchell (2002) found that GPs in general tend to question their own ability to offer adequate palliative care, especially when faced with less common symptoms.

The New Zealand Palliative Care Strategy (Ministry of Health, 2001) identifies rural people with a terminal illness, as a 'subnational' group needing particular attention, as they transition into palliative care. Yet, despite predictions that the relative numbers of older people living, and consequently dying, in rural areas will increase in the future (Dunstan \& Thomson, 2006), and current concerns about health care provision, there is a paucity of literature about rural EoL care for elders. In addition, given the contemporary discourses around ageing in place and dying at home, more understanding of the experience of EoL care for older people living in a rural community is needed.

\section{METHOD}

This study aimed to provide some understanding of rural EoL care for older people. Narrative analysis ${ }^{2}$ was used to analyse the stories of seven carers providing care for elders. While these stories present a partial, incomplete and situated view of the world (Denzin \& Lincoln, 2005), they are rich in contextual detail that enables a deeper understanding of rural EoL care from a lay perspective. Ethical approval for the study was obtained from the Lower South Regional Ethics Committee.

\section{Participants}

Seven participants responded to local media and community notices: four to 
an article in the free newspaper; one to a community notice; and two by word of mouth. The respondents were all women who had cared for someone, over the age of 65 with a terminal illness, within the last eighteen months.

Catherine ${ }^{3}$ was in her seventies and had cared for her spouse. They had lived in the community, where the study took place, for most of their lives. Janet, who was a similar age and had also cared for her spouse had recently moved into the area. Diane owned a rest home, Neroli and Jill were both nurses, and Tavae was a residential care assistant. Lillian, who was also over seventy, worked as an informal and formal carer.

\section{Setting}

The study took place in a rural district of around 20,000 people. All of the participants lived in [town], the main centre for the district. However, older [town] residents tend to self-identify as rural people, given the town's reliance on the agricultural sector and history as a service hub for the surrounding rural districts (Horrell \& Day, 2007). The nearest tertiary care hospital and community hospice were over 100 kilometres away.

\section{Interviews}

The interviews were conversational in style, both to approximate everyday information exchange and support between lay carers and to capture the complexity and subjectivity that is characteristic of everyday talk. Having recently cared for someone with a terminal illness, the first author's own experiences gave her some 'insider' credibility when conducting the interviews. The conversations mainly flowed spontaneously, producing insightful narratives, although at times they were stilted, following the question and answer format.

\section{Analysis}

Six of the interviews were recorded. One participant allowed note-taking only and during several 'conversations' co-produced a set of notes she was comfortable with. Only one other participant took the opportunity to read her transcript. Listening to each interview several times facilitated the recall of the original conversations while transcribing, and heightened the interpretive process as emerging and significant themes were identified. Organising the stories thematically revealed the convergence and divergence between participants around similar issues. During their interviews some individuals expressed contradictory views about the same issue. This highlights the complexity that 
arises from different contextual backgrounds, between individuals and over time for the same individuals. Although there were some positive and uplifting stories, the general tone was quite negative and critical. This reflected the particular agendas participants brought to the interview, which had, for some, been the catalyst for their participation in the study. This may have been due to the newspaper article and information sheet suggesting that their perspectives could help improve future EoL care.

The narratives that elicited an emotional response at the time of the interview, due to feelings of sadness, disbelief, sympathy and admiration, became the focal point for the study. When they served as support or counter-points to the main story, excerpts from other participants were included, even if they did not meet the criteria of a narrative (Riessman, 2008). The results then, are a hybrid of thematic and dialogic narrative analysis (Riessman), using both a case study approach (Radley \& Chamberlain, 2001) as well as a kind of comparative analysis found in grounded theory. It was an eclectic approach, which resonates with Denzin and Lincoln's (2005) metaphor for the qualitative researcher as bricoleur or quilt maker, having stitched together bits and pieces to tell a story that takes on a life of its own.

The following results represent an interpretive quilt, or story, stitched together from the stories of the seven carers. Although the original aim of the study was to tell a rural story, the participants resisted attempts to focus only on the rural aspects of EoL care as their rural way of life was a taken-for-granted part of their every day being. Because most of the participants had little experience of urban EoL they had no basis on which to make comparisons. However, the rural stories emphasise a lack of resources and access to specialist palliative care in rural communities as well as challenging stereotypical perceptions of rural life. The caring stories strongly reflect the participants' social location in a particular time in the history of dying and their ambivalence regarding EoL care. These stories reveal the tension between the 'medical model' which focuses on fighting or curing the physical disease and a person-centered approach that acknowledges the physical, psychological and spiritual dimensions of the 'whole' individual, including them, and their family, in decisions about their own care. 
RESULTS AND DISCUSSION

\section{Rural Communities}

\section{'There's this huge myth out there...'}

Smaller families, filial mobility, and leaving family behind to retire in cheaper rural areas means that older people no longer enjoy the traditional extended family networks that once were characteristic of rural, or pastoral, living (Kellehear, 2007). Neroli, Tavae and Diane, had all provided residential care for rural people who received few visits from family and friends. According to Neroli, an enrolled nurse, with thirty-five years experience:

There's this huge myth out there that all these people have got a family because a lot of them don't. I mean this chap, he used to live in a caravan in the [town] camping ground for years and years and years. I think he's got very few family members anywhere.

Diane provided examples of her rest home residents who had family overseas or were estranged from family:

...we do have people who essentially don't have family, and some who don't have family that bother with them. You know, because of some family dynamics in the past...

Tavae, a residential care assistant for nearly twenty years, showed concern for residents with no family support:

It's quite a lot of people I'd be there for them... when they die alone. I remember I had to hold the hands of one old man; I think he's a little bit scared to go. Was no family there and so I just talked to him and hold his hand and then a few minutes he's gone.

Responding to a question about support from neighbours, Lillian mentioned the changes in rural living she had witnessed during her seventy-plus years, which she attributed to busy working lives and the use of motor vehicles ${ }^{4}$ :

If I look back on my childhood, I can start at the bottom of the hill and tell you the neighbours all around the whole street. On both sides... I would rashly say that if you asked the majority of the people today they would be lucky if they know three to five people in 
their whole street...

On the other hand, Janet told a more traditional story. She spoke, with a great deal of warmth and conviction, about living in a caring, supportive rural community, 'I've got the most wonderful neighbours in the world.' Having recently moved to [town], she and her husband worshipped at a small rural church, where Paul chose to have his ashes buried. Janet frequently brought our conversation back to the church and the care neighbours had shown her, with practical help, information and psychological and spiritual support:

I'd say that I have had love given me more than I ever, ever expected and people thought when I, Paul died, that I would move to [city]... No! I'm very happy here. I have all the support I need. ... and I shall live here for as long as I possibly can...

\section{Providing Around the Clock Care}

However, the community's lack of formal support with night care was a source of stress for Janet:

I kept wakening... what's he doing...hop across, see what he's doing...2 o'clock in the morning, he's pulled out his catheter, he's trying to get over the cot sides... and you know it was just so hard.

Similarly, Catherine found providing 24 hour care stressful:

I got terribly tired...you know I wasn't sleeping because he had a little buzzer thing and if he wanted me, he buzzed me.

In contrast, although a similar age to Janet and Catherine, as a paid carer Lillian worked rotating shifts. She described caring in terms of its rewards:

...that's why I love being a carer, because you share your life, it's not their life, it's not your life, it's combined and by sharing it you enchant two lives.

Lillian was talking about having the time to sit with an elderly gentleman, in his 90 , to reminisce about the past, and recite poetry from their school days. Similarly, Tavae, who worked night shift in a rest home, spoke about her love for her work and the residents, reflecting her cultural background in which elders are respected and dying is a natural part of life: 
...the residents come first, the elderly come first, we leave everything and we go in... we do that to be there for them...the people, that's what we there for, to care for them...like you love your parents that's the way you treat these people.

\section{A Lack of Resources and Specialist Palliative Care}

Most participants spoke about a lack of resources and difficulties accessing specialist palliative care. Neroli told the story of a person who died at the weekend, in a small rural township:

... everybody knew she was terminal, but no plan had been put in place...it took about two and a half hours to locate a morphine pump.

A home death had been planned, but the family did not want the body to remain at home. However, she could not be moved until a doctor certified the death and there was no doctor on duty. In the more remote rural areas it is becoming common for a primary nurse to manage the community after hours, with a duty doctor accessible by telephone as back up. Neroli expressed concern that the whole situation was 'unnecessarily traumatic' for all concerned.

Catherine also referred to the lack of specialist palliative care available in her rural town ...the hospital here weren't really equipped to let people die...they were equipped to keep people alive, an observation that parallels the findings of Goodridge and Duggleby (2010). Janet too, was disappointed with the standard of care provided by the local hospital:

... hospital care was good up to a point, but then I'm an old-timer.

Neroli acknowledged the importance of providing old-fashioned care, but talked about how time pressures and low staffing levels constrain what nurses can do:

So you've got people in rest homes, two nurses on doing their best, having to cope with $35-40$ patients and literally you go in to see if they're dead yet and that's about all you have time to do.

Neroli and Diane both spoke about accessing after hours specialist care for their residents. Neroli, a nurse who was constantly called back on shift to do the 'drug round' framed this in terms of staff shortages. Talking from an 
owner's perspective, Diane discussed the extra costs incurred, especially now that residents have more complex needs and shorter stays than in the past. Although providing specialist palliative care after hours was unlikely to be recovered financially, Diane felt a moral responsibility to ensure her residents received quality care. Given funding issues, it is likely that such care varies between residential facilities if prioritising pain relief, and other medical interventions, depends upon the caring ethic of individual owners.

Lillian relayed one of the most poignant and troubling stories regarding an older couple with no nearby family. She was providing paid home care for a lady in her mid-eighties who was herself caring for an older husband in his 9os. Lillian was convinced that the stress of caring for her dependent spouse hastened her client's death:

... she had to go into hospital because she was sick, so [the husband] had to go into respite care ....after four or five days they would put her out of hospital and send her home... she would be allowed the next three or four days before her husband was sent back from the rest home...that happened three times ...she asked them and begged them and even though the doctor asked for them to keep him, they declined ...they said 'well you've used up your respite care' and she said 'but I've had to go to hospital the three previous trips'... three days after she came home the last time she took sick and died. I'm so angry at that.

\section{Dying at Home}

A subtle, often tacit, pressure exists around the belief that dying at home is preferable, as a natural and necessary component of the ideal or good death, especially in rural areas (Wilson, 2009). This is similar to the morality espoused by the natural birth movement, which promotes the personal virtue of achieving home delivery or eschewing pain relief. The satisfaction of achieving this ideal, is offset by feelings of inadequacy for those who attempt and 'fail'. There may be a risk of this happening with home deaths, when the person who is dying does not die at home, as in the case of Catherine and Graham:

It just isn't possible to be at home. I mean I couldn't give him the care that Hospice did. He didn't want to go to Hospice, but in the final analysis it really didn't make any difference because he didn't know where he was. I felt I let him down. 
Catherine was torn between wanting to keep her husband at home and ensuring that he had the best care available, which meant in the end, 'he couldn't even have his own bed', because an electric bed made lifting and turning easier for the visiting nursing staff. Catherine's story is one of realisation that family are not equipped to care for dying people; rather EoL care is a specialised field, which for the patient's sake is best left to the experts.

While moving care to the home setting is usually in deference to personal wishes it is likely that unskilled family members are unaware of what this entails, especially with regard to the length and extent of care required. People caring for relatives at home may feel the need to be available around the clock, especially partners who take on a larger share of the caregiving burden compared to other caregivers (Rees et al., 2001). However, the physical demands of providing that care are often more than they can cope with. In fact, caregiving is considered one of the most stressful social situations (Overcamp-Martini, 2005). This is understandable, given that most family carers have no formal nursing training, yet the level of care that they are expected to provide, and they themselves want provided, can be as technically complex as that given by trained nurses in a hospital setting. In addition, many carers are women over the age of 65 , with physical limitations.

Often practical support is insufficient, which may be due to a lack of information sharing (Bee et al., 2008). Typically, relatives adopt a 'trial and error' approach to palliative care, picking things up in an ad hoc manner, and making do as they go along. This was certainly Catherine's experience. Unless they self-identify as informal carers and enrol in courses that provide information about caring, including safe lifting techniques, these people risk jeopardising their own health. However, even Janet, who was previously a registered nurse, struggled with the demands placed upon her as the primary carer for her husband at home. In this respect, Catherine's story of Graham not being able to die at home comes as no surprise. A common reason for patient admission to institutions is to relieve family of caregiving responsibilities (Rees et al., 2001). However, the psychological ramifications of not being able to cope with EoL care, 'I felt I let him down' may be as important as the physical burden of caregiving. Even though most people would prefer to be cared for and die at home (Higginson \& Sen-Gupta, 200o), the majority of people in developed countries die in hospital (Gomes \& Higginson, 2008) making it increasingly important to address residential and community hospital care for dying people and their carers. In New Zealand, the number of people in residential care is likely to increase by $83 \%$ between 2001 and 2021, despite the ageing-in-place initiative to support people to stay in their own homes for longer (Cox et al., 2004). 


\section{Caring}

Between two paradigms

As dying moves back into the community with care increasingly being provided by the community (Heaton, 1999), we need to be aware that processes have changed, and that the idealised notion of a good death at home surrounded by loving family and friends may not be a reality for all. It cannot be assumed that traditional support networks still exist, even for people living rurally. Although we might want to reclaim dying as a natural process and part of everyday living, it has become a complex, technologically managed process. The dying phase is lasting longer, symptoms are more complex, medical technology has improved, and with that comes an expectation for a kind of care for which most carers do not have the life experience, the knowledge or the skills to provide. In effect, there is no modern equivalent of the ars moriendi, the medieval guide to dying well, embedded within the fabric of society to guide the actions of today's lay carers. Although Hospice New Zealand offers a Palliative Care for Care Assistants course, the uptake and implementation of this 'specialist' knowledge is limited (Latta, 2007), as is the uptake of information and training offered by various carer support groups in the community, despite continuing requests for more information, education and practical support for dying people and their carers (Phillips \& Reed, 2009). The stories presented here suggest that people are struggling with changing contexts for dying, at home, and in residential care.

The people in this study are poised between two different paradigms of care for dying people. In other words, their 'personal troubles' reflect a particular socio-historical moment (Mills, 2000). As a result, the participants' stories convey a degree of ambivalence towards EoL care. A caring ethic has been a lived experience for them, learned as a part of growing up. At the same time, although they may have had no direct experience of dying in today's world, they are aware of medical advances. So, on the one hand, they value traditional, empathic ways of caring, but on the other hand, they want and expect the best of modern medical care. In order to create a balance between the two worldviews, lay carers will need to work at creating and maintaining partnerships with health professionals, just as health professionals need to incorporate patient-centred care as part of best practice. Otherwise, there is a danger that EoL care will remain a specialised field, albeit more visible as it moves into the community. Neroli was concerned that lay people no longer know the proper procedures: 
...it still seems to be the family's responsibility to find out what help is available for them, rather than a person being put in charge of organising the support...we haven't got the support services to deal with it. If you are somewhere like [city], the palliative care is absolutely fantastic, mainly through the hospice, so if you are dying of something other than cancer I don't know if you fall through the gaps or not.

She compared dying with being born in terms of support, preparation and knowledge:

...whereas when we are born it all just gets thrown into action doesn't it?...you had the midwife visiting and it just all got organised for you... why is it that when babies are born, we all know they have to have this checked and that checked, but here you and I are sitting, obviously both over 25 and we don't even know what the legalities of [dying] all are and I've been working in this profession forever!

Neroli's observation of society's differential treatment of birth and death suggests that we are still living in the shadow of a society where death and dying was taboo. This echoes O'Reilly's words from almost ten years ago, that, 'dying care, like birthing care, should be available where people want it, and it should be quality care wherever it is given' (2000, p. 16).

Quality of Care: to treat or not to treat?

Ambivalence features strongly in the participants' stories about medical intervention, highlighting the tension between medicine's curative focus and the post-modern expectation that individuals, and their families, should be able to choose when to stop treatment. Creating the most division between the participants, depending on previous experience and personal background, this issue was generally framed in terms of a concern for quality, as opposed to quantity, of life. Janet, having recently cared for her husband, said:

What I saw happening to Paul, the cure was worse than the disease... but it had to be Paul's decision and he wanted it, because he wanted to live... when my time comes I'll be very happy just to slip away and I believe that if Paul had never had any chemotherapy he would have had a longer and more full life.

and, 
I said, 'boys this is just nonsense'. Everyone was trying to do things for Dad and all they needed to do was just accept our Dad is not going to live...so what we need to do is give him some quality time.

Catherine echoed these sentiments, 'I knew he had had enough and he just wanted to be left to die... but we kept getting these interventions.' Similarly, the catalyst for Jill's participation in the study had been a doctor's comment, 'You can't let a patient starve or dehydrate to death.' Jill believed that:

When patients get to the stage of not eating [or] drinking [and] suffering major weight loss they should let nature take it's course... [instead, doctors] try to prolong life, regardless ...they keep them going to do it all over again.

Later in the interview, Jill acknowledged that how she cared for a person changed depending on her role as a carer. Talking about caring, while offduty, for a relative who was imminently dying, she said she resisted nursing intrusions such as routine turning. Although she offered assistance, the nurses joked with her saying, 'now you are being the nurse' and 'now you are being the [relative].' Jill also suggested that, 'some decisions not to treat are easier to make because of age.' On the other hand, Tavae, angry about a personal experience where treatment for a resident in her care had been withheld because of age, had this to say:

They said in the hospital they prefer not to treat them because they are old...she said we not wasting the medication for people like her, and I was really, really angry and said, 'that is your job'. I said, 'you should do something about this, she pay her tax, everything, she old'.

Tavae felt that this was morally wrong. It was this experience that motivated Tavae to volunteer for the study.

\section{Therapeutic Relationships}

Just as the dilemma over providing or with-holding treatment polarised the participants, having the time to form therapeutic relationships and 'just being there' were unambiguously considered key components of EoL care. There are times when listening is as important as finding answers to tricky questions or offering hope in terms of technological cure, hence Kleinman's (1988) argument for empathic witnessing as an important aspect of care. Catherine found it upsetting that the nurses had no time to treat the patients as people, say- 
ing, 'they're busy, put it that way.' She said, 'I used to go down every mealtime and feed him, when he was in there, otherwise he wouldn't have eaten.' Janet spoke about a turning point in her husband's care due to what she perceived as neglect in the local hospital:

.... and he's sitting in a chair, slumped over like this, bare feet, no blanket or anything over him... an indication from God to say to me, take him home Janet you can do better than this.

She found it inexcusable that the nurses did not have the time to provide basic, old-fashioned nursing care, even though they might have wanted to. Neroli, a nurse, commented:

It's not about, you know, the two hourly turns and the pressure areas and the toileting and na na na, it's about taking the time to get to know the person.

On the other hand, Lillian who had the time to build a relationship with her elderly client said, 'instead of being frightened by [him dying] I just had an overwhelming, just love of life and love of being there for him.'

Diane told the story of a special relationship between a resident and her staff. Having been sent from hospital with instructions that he should be given only ice chips to suck, he showed a desire for more, so the carers introduced a soft diet. He lived a further 3 months, maintaining what Diane believed was a good quality of life. When he fell and broke his femur he asked to be transferred back from hospital, because he did not want to die there. The residential facility had become his 'home. It was clear that a special reciprocal relationship had developed between this resident and the staff and that how he had lived until he died remained as a good memory for all of those involved in his care.

A report from the Institute of Medicine (2001) states that patient-centred care, which is respectful and responsive to patient needs and abilities to make decisions, is quality care. In this vein, Branch (2000), MacLeod $(2000,2001)$ and Lloyd (2004) all talk about caring in terms of having empathy, compassion and respect for others. Branch in particular describes the need to build and maintain therapeutic relationships. This, he argues, is best achieved by getting to know patients, trying to understand their viewpoint and background and then negotiating a plan for care, together. Buetow (2005) calls this 'co-providing', whereby physicians, patients and their caregivers have equal input. While a more balanced relationship is desirable, older people in particular tend to 
have high regard for professional opinion and may feel uncomfortable with or unwilling to take part in an 'equal' partnership. However given time, relationships can be built based around mutual trust and respect. Unfortunately, from the perspective of the participants in this study, time was a missing dimension in their experience of EoL care.

MacLeod (2000) argues that as part of their training and medical socialisation, medical students lose the compassionate attributes that led them into medicine in the first place, learning instead to be professionally and emotionally detached. Interestingly, several participants argued that empathic caring is 'not something that you can learn', but is something that you have, 'the love in you can do the work. One of the nurses in this study spoke about professional boundaries, identifying detachment as necessary for her personal and emotional safety. She said that she is always too busy to attend any kind of 'debriefing' session after a patient's death, and furthermore it is difficult to get everybody together, because the nurses work different shifts. Although the hospital where she works offers individual counselling, she never takes up the offer, preferring to work through issues on her own, or taking a holiday when she 'burns out'.

\section{CONCLUSION}

The conclusions drawn from this research are summarised in terms of disrupting stereotypical assumptions about rural people, emphasising the importance of relationship-building as a quality EoL care resource, and finding time to 'just be there' for dying people, and their families. Firstly, the participants' multiple and complex experiences remind us that rural people are not a homogenous group. Ageing, and dying, in a close-knit, supportive community is not a universal experience. Each person's expectations are best understood from their own standpoint; coloured by their personal characteristics and background yet at the same time nested within a particular set of family or community circumstances and wider socio-historical factors, which influence the kind of care expected and received. Preferences and expectations vary between patients, between family members and may change over time as illnesses progress. This kind of complexity reinforces the notion that caring requires the recognition of difference, which takes time and involvement (Frank, 1991), and therefore a one-size-fits-all approach often falls short of providing best quality care.

At the same time, these stories highlight how difficult it is to provide the sort of rural EoL care that will meet everybody's standards and expectations. If 
we cannot assume that someone will be available, willing or able to provide the kind of care that enables dying people to remain at home until their final hour, then rural EoL care planning needs to consider more fully the options provided by rest homes and community hospitals. Providing more specialist palliative care support and including the qualities of 'home' in residential facilities would improve the experience of EoL care for all concerned. Increased awareness of the positive aspects of residential care, perhaps from the residents' perspectives, would lessen the stigma surrounding these facilities, leading to more informed choices about place of death.

Secondly, this research highlights the importance of having the time to form and maintain caring relationships. This was a common thread that ran through all of the participants' stories; expressed as gratitude when this kind of care was present, and disappointment and even anger when it was not. This appreciation for the therapeutic benefit of interconnectedness that results from meaningful relationships suggests that we need to re-visit the current focus on independence, autonomy and individual choice. Getting to know patients, their families and their circumstances and being able to work together in collaborative 'partnerships' has the potential to move us closer to 'getting services right for those sick enough to die' (Dy \& Lynn 2007, p.511). Sometimes that may be as simple as 'just being there' for someone who is dying. This was mentioned frequently by the participants and parallels McKee et al.'s (2010) study of rural hospice volunteers. Having the time to talk with people, to listen, to appreciate their unique perspectives, and to form caring, meaningful relationships are key concepts for quality EoL care, wherever it is delivered. It must not be assumed that this kind of care and support is the norm for all older people simply because they live rurally.

\section{NOTES}

1 International research forms the basis of the rural literature review.

2 The first author conducted all the interviews and did the transcribing and analysis.

3 Pseudonyms have been used for the purpose of confidentiality.

4 The longer excerpts from the interviews are presented as composite narratives, which have been edited for the sake of brevity. The omitted material does not detract from the overall meaning. 


\section{REFERENCES}

Bee, P.E., Barnes, P., \& Luker, K.A., 2008. A systematic review of informal caregivers' needs in providing home-based end-of-life care to people with cancer. Journal of Clinical Nursing, 18(10), pp.1379-1393.

Branch, W.T., 20oo. The ethics of caring and medical education. Academic Medicine, 75(2), pp.127-132.

Buetow, S.A., 2005. To care is to coprovide. Annals of Family Medicine, 3(6), pp. 553-555.

Byock, I., Norris, K., Curtis, J.R., \& Patrick, D.L., 2001. Improving end-of-life experience and care in the community: a conceptual framework. Journal of Pain and Symptom Management, 22(3), pp.759-772.

Casey, M.M., Moscovice, I.S., Virnig, B.A., \& Durham, S.B., 2005. Providing hospice care in rural areas: challenges and strategies. American Journal of Hospice and Palliative Medicine, 22(5), pp.363-368.

Chalmers, A.I., \& Joseph, A.E., 1998. Rural change and the elderly in rural places: commentaries from New Zealand. Journal of Rural Studies, 14(2), pp.155-165.

Corr, C.A., Doka, K. J., \& Kastenbaum, R., 1999. Dying and its interpreters: a review of selected literature and some comments on the state of the field. Omega, 39(4), pp.239-259.

Cox, M., Hope, S., \& Davies, P., 2004. Ageing New Zealand and health and disability services: demand projections and workforce implications, 20012021. Available at: http://www.moh.govt.nz/moh.nsf/pagesmh/3716?Open [Accessed 4 December 2009].

Crosato, K.E., \& Leipert, B., 2006. Rural women caregivers in Canada. Rural and Remote Health, 6(520). Available at: http://www.rrh.org.au/articles/ showarticlenthamer.asp? ArticleID=520 [Accessed 4 December 2009].

Davis, S., \& Bartlett, H., 20o8. Healthy ageing in rural Australia: issues and challenges. Australasian Journal on Ageing, 27(2), pp.56-60.

Denzin, N.K., \& Lincoln, Y. S., 2005. Introduction. In: N. Denzin \& Y. Lincoln, eds. The Sage handbook of qualitative research. $3 \mathrm{rd}$ ed. Thousand Oaks (CA): 
Sage Publications.

DeSpelder, L.A., \& Strickland, A.L., 2005. The last dance: encountering death and

dying. 7 th ed. Boston (MA): McGraw-Hill.

Dunham, W., Bolden, J., \& Kvale, E., 2003. Obstacles to the delivery of acceptable standards of care in rural home hospices. American Journal of Hospice and Palliative Medicine, 20(4), pp.259-261.

Dunstan, K., \& Thomson, M., 2006. Demographic aspects of New Zealand's ageing population. Statistics New Zealand Tatauranga Aotearoa. Available at: http://www.stats.govt.nz/reports/Papers/demographic-aspects-nz-ageingpopulation.aspx [Accessed 4 December 2009].

Dy, S. \& Lynn, J., 2007. Getting services right for those sick enough to die. British Medical Journal, 334, pp.511-513

Evans, R., Stone, D., \& Elwyn, G., 2003. Organizing palliative care for rural populations: a systematic review of the evidence. Family Practice, 20(3), pp.304-310.

Feifel, H., 1990. Psychology and death: meaningful rediscovery. American Psychologist, 45(4), pp. 537-543.

Frank, A.W., 1991. At the will of the body: reflections on illness. Boston: Houghton Mifflin.

Gomes, B., \& Higginson, I. J., 2008. Where people die (1974-2030): past trends, future projections and implications for care. Palliative Medicine, 22, pp.3341.

Goodridge, D., \& Duggleby, W. 2010. Using a quality framework to assess rural palliative care. Journal of Palliative Care, 26(3), pp.141-149.

Gott, M., Seymour, J., Bellamy, G., Clark, D., et al., 2004. Older people’s views about home as place of care at the end of life. Palliative Medicine, 18, pp. $460-467$.

Heaton, J., 1999. The gaze and visibility of the carer: a Foucauldian analysis of the discourse of informal care. Sociology of Health \& Illness, 21(6), pp.759-777. 
Hedtke, L., \& Winslade, J. 2004. Re-membering lives: conversations with the dying and the bereaved. Amityville, (NY): Baywood Publishing Company.

Higginson, I.J., \& Sen-Gupta G.J.A., 200o. Place of care in advanced cancer: a

qualitative systematic literature review of patient preferences. Journal of Palliative Medicine, 3(3), pp. 287-30o.

Horrell, B., \& Day, L. 2007. Ageing in place: a good life? Unpublished report for the Waitaki District Council.

Hospice New Zealand. 2005. Find a hospice. Available at: http://www.hospice.org. $\mathrm{nz} / \mathrm{cms}$ _display.php?sn=18\&st=\&pg=1248 [Accessed 4 December 2009].

Institute of Medicine. 2001. Crossing the quality chasm: a new health system for the 21st century. Washington, (D.C): National Academy Press.

Kellehear, A., 2007. A social history of dying. New York: Cambridge University Press.

Kelley, M. 2007. Developing rural communities' capacity for palliative care: a conceptual model, Journal of Palliative Care, 23(3), pp.143-153.

Kelley, M.L., Habjan, S., \& Aegard, J., (2004). Building capacity to provide palliative care in rural and remote communities: does education make a difference? Journal of Palliative Care, 20(4), pp.308-315.

Kleinman, A., 1988. The illness narratives: suffering, healing, and the human condition. New York: Basic Books.

Latta, L., 2007. Exploring the impact of palliative care education on care assistants employed in aged care facilities in Otago, New Zealand. Unpublished Master's thesis. Dunedin, New Zealand: Otago Polytechnic.

Lloyd, L., 2004. Mortality and morality: ageing and the ethics of care. Ageing \& Society, 24, pp. 235-256.

McKechnie, R.C., MacLeod R.D., \& Keeling S. 2007. Facing uncertainty: the lived experience. Palliative and Supportive Care, 5, pp. 255-264.

McKee, M., Kelley, M., Guirguis-Younger, M., MacLean, M., \& Nadin, S. 2010. It 
takes a whole community: the contribution of rural hospice volunteers to whole-person palliative care. Journal of Palliative Care, 26,(2), pp.103-111.

MacLeod, R., 20oo. Learning to care: a medical perspective. Palliative Medicine, 14, pp. 209-216.

MacLeod, R., 2001. On reflection: doctors learning to care for people who are dying. Social Science \& Medicine, 52(11), pp.1719-1727.

McNaught, A.J., 2002. A death of one's own: understanding dying well for patients receiving palliative care. Doctoral thesis. Palmerston North, New Zealand: Massey University.

Mills, C.W., 200o. The sociological imagination. Oxford: Oxford University Press.

Ministry of Health. 2001. The New Zealand palliative care strategy. Wellington: Ministry of Health.

Ministry of Health. 2002. Health of older people strategy: health sector action to 2010 to support positive ageing. Wellington: Ministry of Health.

Ministry of Social Development. 2001. Positive ageing in New Zealand: diversity participation and change: he organa kaumatua i Aotearoa. Wellington: Ministry of Social Development.

Ministry of Social Development. 2008. The New Zealand Carers' Strategy and Five-Year Action Plan. Wellington: Ministry of Development.

Mitchell, G.K., 2002. How well do general practitioners deliver palliative care? A systematic review. Palliative Medicine, 16(6), pp.457-464.

O’Reilly, M., 200o. Dying in an acute-care setting. Kai Tiaki: Nursing New Zealand, 6(10), pp.16-17.

Overcamp-Martini, M.A., 2005. Institutionalization and residential living. In: C. Dulmus, \& L. Rapp-Paglicci, eds. Handbook of preventive interventions for adults. Hoboken, (NJ): John Wiley. Ch.19.

Payne, S., Kerr, C., Hawker, S., Seamark, D., et al., 2001. Community hospitals: an under-recognized resource for palliative care. Journal of the Royal Society of Medicine, 97, pp.428-431. 
Phillips, L.R., \& Reed, P.G., 2009. Into the abyss of someone else's dying: the voice of the end-of-life caregiver. Clinical Nursing Research, 18(1), pp.80-97.

Putnam, R.D., 2000. Bowling Alone: the collapse and revival of American community. New York: Simon \& Schuster.

Radley, A., \& Chamberlain, K., 2001. Health psychology and the study of the case: from method to analytic concern. Social Science \& Medicine, 53, pp.321-332.

Rees, J., O’Boyle, C., \& MacDonagh, R., 2001. Quality of life: impact of chronic illness on the partner. Journal of the Royal Society of Medicine, 94(11), pp. 563-566.

Riessman, C.K., 2008. Narrative methods for the human sciences. Thousand Oaks, (CA): Sage Publications.

Seale, C., 1998. Constructing death: the sociology of dying and bereavement. Cambridge: Cambridge University Press.

Seymour, J., Witherspoon, R., Gott, M., Ross, H., et al., 2005. End-of-life care: promoting comfort, choice and well-being for older people. Bristol, U.K: The Policy Press.

Twycross, R., 2007. Patient care: past, present, and future. Omega, 56(1), pp.7-19.

van Vorst, R.F., Crane, L.A., Barton, P.L., Kutner, J.S., et al., 20o6. Barriers to quality care for dying patients in rural communities. Journal of Rural Health, 22(3), pp. 248-253.

Walker, S., \& Macleod, R., 2005. Palliative care knowledge of some South Island GPs. NZFP, 32(2), pp. 88-93.

Walter, T., 1994. The revival of death. London: Routledge.

Wilkes, L.M., \& White, K., 2005. The family and nurse in partnership: providing day-to-day care for rural cancer patients. Australian Journal of Rural Health, 13 , pp.121-126.

Wilkes, L.M., White, K., \& O’Riordan, L., 20oo. Empowerment through information: supporting rural families of oncology patients in palliative care. Australian Journal of Rural Health, 8, pp.41-46. 
Article $\cdot$ Horrell \& Stephens

Wilson, D., Fillion, L., Thomas, R., Justice, C., et al. 2009. The 'good' rural death: a report of an ethnographic study in Alberta, Canada. Journal of Palliative Care, 25(1), pp.21-29.

Wilson, D., Justice, C., Sheps, S., Thomas, R., et al., 2006. Planning and providing end-of-life care in rural areas. The Journal of Rural Health, 22(2), pp.174-181. 